\title{
Impacts of survival and reproductive success on the long-term population viability of reintroduced great bustards Otis tarda in the UK
}

\author{
Kate Ashbrook, Andrew Taylor, Louise Jane \\ IAN CARTER and Tamás SZÉkELY
}

\begin{abstract}
Reintroductions aim to re-establish species within their historical ranges through the release of wild- or captive-bred individuals following extirpation (or extinction) in the wild. There is no general agreement on what constitutes a successful reintroduction but the probability of the population achieving long-term persistence should be addressed. Here we review a 10-year trial reintroduction of the great bustard Otis tarda, a globally threatened bird species, to the UK and assess the long-term population viability. Despite changes in rearing and release strategy, initial post-release survival probability remained consistently low, with only $11.3 \%$ of bustards $(n=167)$ surviving from release to 1 year post-release. Nineteen breeding attempts were made by eight females; however, only one chick survived $>100$ days after hatching, and no wild juveniles have recruited into the population. Using demographic rates from the UK population and wild populations elsewhere, and stochastic population modelling, we investigate the viability of this reintroduced population by predicting population size over the next 10 years. Under current demographic rates the population was predicted to decline rapidly. Self-sufficiency was predicted only using the highest estimates from the UK population for first-year and adult survival, and recruitment rates from wild populations elsewhere. Although changes have been made in rearing, release strategies, habitat management and release sites used, these changes appear to have a modest effect on long-term viability. Substantial improvements in survival rates and productivity are necessary to establish a viable great bustard population in the UK, and we consider this unlikely.
\end{abstract}

Keywords Captive rearing, conservation, habitat management, monitoring, release strategy

\footnotetext{
KATE AshBrooK* (Corresponding author) and TAMÁs SzÉKelY Department of Biology and Biochemistry, University of Bath, Bath BA2 7AY, UK

E-mail k.ashbrook@worc.ac.uk

Andrew TAylor and Louise JANe Royal Society for the Protection of Birds, Sandy, Bedfordshire, UK

IAN CARTER Natural England, Whittington Road, Worcester, UK

${ }^{*}$ Current address: Institute of Science and the Environment, University of Worcester, Worcester WR2 6AJ, UK

Received 6 January 2015. Revision requested 6 February 2015.

Accepted 3 March 2015. First published online 26 June 2015.
}

\section{Introduction}

D eintroduction projects attempt to re-establish species - within their historical ranges through the release of wild- or captive-bred individuals following extirpation or extinction in the wild (IUCN, 1998; Ewen et al., 2012). They have become an important tool in conservation management; however, many reintroduced populations fail to establish and it is often unclear whether these failures are a result of ad hoc methodologies and management or simply the limited success of released individuals (Wolf et al., 1996; Fischer \& Lindenmayer, 2000). The poor success of reintroductions worldwide has resulted in a drive towards the identification of rigorous research and monitoring targets identified a priori and the use of adaptive management to overcome uncertainty in the choice between various conservation management actions (Armstrong \& Seddon, 2008; Schaub et al., 2009; Ewen et al., 2012).

Although there is no general agreement on what constitutes a successful reintroduction (Seddon, 1999), reintroductions typically aim to establish a free-living, selfsustaining population through three main objectives: (1) survival of individuals after release, (2) settlement of individuals into the release area, and (3) successful reproduction and recruitment into the population (Griffith et al., 1989; Sarrazin \& Barbault, 1996; Teixeira et al., 2007). A key question that needs to be addressed by reintroduction projects is whether the population can achieve long-term persistence (Armstrong \& Seddon, 2008), where recruitment from breeding individuals compensates for (or exceeds) adult mortality (Sarrazin \& Barbault, 1996). In the initial stages of a reintroduction there is much uncertainty concerning demographic rates and the suitability of habitat for supporting the reintroduced population, and population modelling typically focuses on predicting population growth and aims to highlight limiting factors (Armstrong \& Reynolds, 2012). When reintroduced individuals survive the establishment phase and demographic data from monitoring are more readily available, population modelling can be used to explore the effects of various management decisions and estimate how many more releases are required to ensure long-term viability of the population (Oro et al., 2008; Schaub et al., 2009; Armstrong \& Reynolds, 2012).

Here we assess the long-term persistence of a reintroduced population of the globally threatened great bustard Otis tarda in the UK. The great bustard was a common 
TABLE 1 The number of great bustard Otis tarda eggs collected and hatched in source populations in Russia and Spain, the number of eggs and chicks transported from these populations to the UK, and the number of juveniles released in a reintroduction trial in the UK during 2004-2014.

\begin{tabular}{|c|c|c|c|c|c|c|c|c|}
\hline & $2004-2008$ & 2009 & 2010 & 2011 & $2012^{1}$ & 2013 & $2014^{2}$ & Total \\
\hline Source population & Russia & Russia & Russia & Russia & Russia & & Spain & \\
\hline No. of eggs collected & 232 & 48 & 46 & 60 & 42 & 0 & 56 & 484 \\
\hline No. of eggs hatched & 154 & 38 & 32 & 49 & 35 & 0 & 44 & 352 \\
\hline No. of chicks transported to the UK & 102 & 26 & 25 & 35 & 9 & 0 & 2 & 199 \\
\hline No. of juveniles released in the UK & 86 & 18 & 23 & 29 & 11 & 0 & 33 & 200 \\
\hline
\end{tabular}

${ }^{1}$ In 2012 six eggs and nine chicks were imported from Russia.

${ }^{2}$ In 201454 eggs and two chicks were imported from Spain.

breeding bird across large parts of Europe and Asia during the 18th century but as a result of hunting, egg collection and changes in agricultural practice it experienced significant declines and local extinctions across its range during the 2oth century (Palacín \& Alonso, 2008) and is now categorized as Vulnerable on the IUCN Red List (IUCN, 2014). Great bustards became extinct in the UK in the 1830s, and attempts to rear the species for reintroduction began in the 1970 . Following a rigorous feasibility study based on IUCN reintroduction guidelines, a 10-year trial reintroduction programme was initiated in 2004. The first 5 years of the reintroduction trial demonstrated that great bustards can be hatched in captivity from wild-collected eggs, and juveniles can be translocated from Russia and successfully released into the wild in the UK (Burnside et al., 2012). Although some released birds reached maturity, a major limitation on project success was the high mortality of juveniles in the first 6 months following release (Burnside et al., 2012).

Here we present results from the 10-year trial reintroduction of great bustards to the $\mathrm{UK}$, and investigate the long-term viability of the reintroduced population. We have three objectives: (1) to determine survival rates from release to 1 year postrelease and test whether various rearing or release strategies adopted during the project improved survival rates; (2) to calculate adult survival rates over the project period; and (3) to use these age-specific survival rates and data on the recruitment of individuals from breeding over the reintroduction period to investigate the long-term viability of the population. Using several population scenarios, incorporating current demographic rates and demographic rates from wild populations elsewhere, we aim to provide evidence-based information on potential future population size and persistence to help inform management decisions.

\section{Methods}

\section{Release methodology}

During 2004-2012 chicks or eggs were imported from Russia and in 2014 eggs were imported from Spain (Table 1); all were reared in a purpose-built facility (for details see Burnside et al.,
2012). The number of eggs collected varied between years, ultimately influencing the number of eggs and chicks imported and released (Table 1). During the first 8 years of reintroduction Russian chicks were imported at 4-10 weeks of age (Burnside et al., 2012); in the ninth year, six eggs were imported and reared in the UK, as well as nine chicks reared in Russia, similar to previous years. In 2013 there was a change in the regulations on exporting great bustard chicks from Russia, and neither eggs nor chicks were imported or released that year. In 201454 eggs and two chicks were imported from Spain (Table 1). Mean hatching success of artificially incubated eggs during 2004-2014 was 70.9 \pm SE 5.7\%. During 20042008 the total number of bustards released was 86 , and despite problems with import regulations an additional 114 bustards were released during 2009-2014.

All individuals released during 2004-2010 were released at site A, which was established in 2004. A second release site (site B) was established in 2011, and in that year the release cohort was split between the two sites (16 juveniles released at site A and 13 at site B). In 2012 we released six juveniles at site $B$, and five juveniles hatched from eggs and reared in the UK were released at site A. In 2014 we set up a third release site (site $\mathrm{C}$ ) and the release cohort was split between sites B and C (17 juveniles at site B and 16 at site C). During 2004-2008 juveniles were released from a 30-day biosecure quarantine unit into a 7 ha opentopped release pen, from which they were free to leave (so-called hard release). From 2009 the first trials of soft release began, in which after quarantine individuals were held for c. 7 days in a mesh pen within the larger release pen, where they could habituate to their new environment. This release methodology was used during 2009-2011; in 2012 and 2014 this approach was combined with an extended period of rearing with dehumanization suits; individuals were led into the release pen on a regular basis, allowing them to stretch, practise flying and develop foraging skills (termed soft release with dehumanization suits).

Following the monitoring methodology described in Burnside et al. (2012) we monitored released individuals regularly year-round, and intensively during the breeding season (March-June) and the first 6 months post-release around release areas. Furthermore, we followed up reports 
of resightings received via website and telephone, and when dead individuals were recovered post-mortems were performed by a vet. This review covers the period from 30 April 2004, when the first eggs were collected, to 30 November 2014, 4 months after the 2014 cohort of birds was released and by which time the oldest surviving released bustard was 10 years and 5 months old.

During 2004-2011 released birds were marked individually with wing-tags (colour-coded according to the year of release); in 2012 and 2014 they were tagged with British Trust for Ornithology metal leg-rings and Darvic plastic colour rings. Argos/GPS enabled LC4 platform transmitter terminals (Microwave Telemetry Inc., Columbia, USA) were fitted to 19 males (105 g device) and 15 females (40 g device) during 2007-2011 to provide daily information on location, which could be accessed remotely. Radio transmitters (Biotrack, Wareham, UK) were also fitted, using a variety of mount types: back-mounted (10 males and 10 females in 2004), necklace-mounted (17 females in 2005, 2006 and 2011) and tail-mounted (24 males and 14 females during 2005-2010).

\section{Estimating reproductive and survival parameters}

We investigated survival probabilities for first-years and adults by compiling histories of live resighting and recovery of dead individuals for 167 released birds during 2004-2012; we did not include individuals released in 2014 as they had only been released 4 months prior to the time of writing. Only juvenile bustards that were released and able to form part of the wild population were included in the analysis; individuals that became disabled during captive-rearing (e.g. damaged wings) and were released into the project release pen were excluded as they were unable to leave the pen and therefore remained captive. Date of marking was considered to be the day of the bird's release, and annual intervals were set from the date of each individual's release, for a maximum of 10 years. Release dates varied between years, from 26 August to 17 October; one bird from 2011 and five from 2012 over-wintered in the main release pen and were able to join the wild population outside the release pen from March onwards in the following year. For these birds the date when they were considered to be free-flying was taken as their release date.

Firstly, we investigated the role of sex and various release methodologies in survival from release to 1 year post-release, using Burnham's joint live resighting and dead recovery models (Burnham, 1993), in MARK v. 7.1 (White \& Burnham, 1999) via RMark v. 2.1.7 in $R$ v. 3.0.2 (R Development Core Team, 2013). Models were specified with survival probability dependent on sex, release year, release month (January, June, July, August, September or October), release site (A or B), release methodology (hard release, soft release, over-winter in release pen, or soft release with dehumanization suits), and transmitter type fitted (satellite (platform transmitter terminal), tail-mounted, necklace-mounted or back-mounted radio transmitter, or no transmitter). As the probability of resighting and recovery was likely to be dependent on whether or not an individual was fitted with a transmitter, and whether the data from the transmitter were accessible remotely, we specified models with probabilities of resighting and recovery dependent on transmitter type, sex (females are smaller and less conspicuous than males), or both of these factors, or with constant probabilities. Secondly, following Doherty et al. (2012) we created all combinations of models, yielding a candidate set of 56 models, and ranked models according to corrected Akaike's Information Criterion (AICc; Burnham \& Anderson, 1998).

Only 17 of 167 free-ranging individuals survived from release to 1 year post-release, and as their release times were staggered over 8 years, individuals provided various amounts of data, depending on their release year. Adults generally returned to their release area every spring and were resighted throughout the year, typically at least once per month. The longest period between resightings was 197 days. If an individual was not resighted within a year we assumed it was dead. We calculated age-specific annual survival ( $S a$, e.g. survival for 1-2 years post-release) for individuals of all ages as $S a_{t+1}=N_{t+1}-N_{t}$, where $N_{t}$ is the number of individuals from one release year age-cohort in a given year and $N_{t+1}$ is the number of individuals in the same release year age-cohort 1 year later, and then calculated the mean annual adult survival $(\overline{S a})$.

\section{Population modelling}

Based on Burnside et al. (2012) we developed new models using the demographic parameters from 2004-2012 to investigate population growth and persistence for the next 10 years. To estimate the size of the founder population at time $t\left(N_{t}\right)$, we used the deterministic model

$$
N_{t+1}=N_{t} \overline{S a}+I \times S_{\text {post }}+\frac{N_{t}}{2} \times r
$$

where $\overline{S a}$ is the mean annual adult survival, $I$ is the number of individuals released, $S_{\text {post }}$ is first-year survival, and $r$ is recruitment into the population from breeding (survival of chicks from hatching to 1 year old). Sex ratio in wild populations elsewhere is variable (Oparin et al., 2003; Martín et al., 2007); in the UK population, sex ratio is relatively equal, and therefore we assumed an equal sex ratio in the analysis. We modelled 10 scenarios (Table 4). Firstly, we simulated population size over 10 years if the reintroduction were to continue releasing 20 or 40 juveniles annually, with the current demographic rates from the UK population ( 1 and 2, respectively). Secondly, to explore the conditions required for the population to become self-sufficient without further releases, we modelled eight other scenarios: using the 
TABLE 2 Summary of model selection from first-year survival models for great bustards in the UK reintroduction trial, with degrees of freedom, corrected Akaike's information criterion (AICc), $\Delta \mathrm{AICc}$, and weight. Survival probability $\left(S_{i}\right)$ was specified as dependent on year of release, release site, release methodology (method), month of release (month), sex, transmitter type fitted (attachment), or constant (.). The probability of resighting a live individual $\left(p_{i}\right)$ and recovering a dead individual $\left(r_{i}\right)$ was specified as dependent on transmitter type (mark), sex, an interaction between attachment type and sex (mark - sex) or as constant (.). The probability that individuals remained in the sampling area $\left(F_{i}\right)$ was held constant.

\begin{tabular}{|c|c|c|c|c|c|}
\hline Model no. & Model & $\mathrm{df}$ & $\mathrm{AICc}$ & $\Delta \mathrm{AICc}$ & Weight \\
\hline 1 & $\mathrm{~S}$ (attachment); $\mathrm{p}(.) ; \mathrm{r}($ attachment $) ; \mathrm{F}()$. & 12 & 296.63 & 0.00 & 0.44 \\
\hline 2 & $\mathrm{~S}(.) ; \mathrm{p}(.) ; \mathrm{r}($ attachment $) ; \mathrm{F}()$. & 8 & 297.85 & 1.22 & 0.24 \\
\hline 3 & $\mathrm{~S}($ site $) ; \mathrm{p}(.) ; \mathrm{r}($ attachment $) ; \mathrm{F}()$. & 9 & 300.07 & 3.44 & 0.08 \\
\hline 4 & $\mathrm{~S}(\operatorname{sex}) ; \mathrm{p}(.) ; \mathrm{r}($ attachment $) ; \mathrm{F}()$. & 10 & 300.32 & 3.69 & 0.07 \\
\hline 5 & $\mathrm{~S}$ (method); $\mathrm{p}(.) ; \mathrm{r}$ (attachment); F(.) & 11 & 300.64 & 4.01 & 0.06 \\
\hline 6 & $\mathrm{~S}($ attachment $) ; \mathrm{p}(\operatorname{sex}) ; \mathrm{r}($ attachment $) ; \mathrm{F}()$. & 14 & 301.30 & 4.67 & 0.04 \\
\hline 7 & $\mathrm{~S}(.) ; \mathrm{p}(\mathrm{sex}) ; \mathrm{r}($ attachment $) ; \mathrm{F}()$. & 10 & 302.31 & 5.68 & 0.03 \\
\hline 8 & $\mathrm{~S}($ site $) ; \mathrm{p}(\mathrm{sex}) ; \mathrm{r}($ attachment $) ; \mathrm{F}()$. & 11 & 304.57 & 7.94 & 0.01 \\
\hline 9 & $\mathrm{~S}(\mathrm{sex}) ; \mathrm{p}(\mathrm{sex}) ; \mathrm{r}($ attachment $) ; \mathrm{F}()$. & 12 & 304.87 & 8.24 & 0.01 \\
\hline 10 & $\mathrm{~S}$ (method); $\mathrm{p}($ sex $) ; \mathrm{r}$ (attachment); F(.) & 13 & 305.25 & 8.62 & 0.01 \\
\hline
\end{tabular}

recruitment rate from the UK population $(\mathrm{r}=0)$ and either (3) the mean annual adult survival in the UK population (the scenario most closely reflecting population dynamics if the reintroduction project is halted in 2015) or (4) high annual adult survival (upper 95\% confidence limit of calculated $\overline{\mathrm{Sa}}$ ); (5) recruitment rates from a wild population $(\mathrm{r}=0.14 \pm \mathrm{SE}$ 0.09; Morales et al., 2002) with mean UK adult survival rates; and (6) recruitment rates from a wild population $(r=0.14 \pm$ SE 0.09; Morales et al., 2002) with high UK annual adult survival (upper 95\% confidence limit of calculated $\overline{S a}$ ). In models $3^{-6}$ we assigned mean $S_{\text {post }}$ to 33 individuals released in 2014; in addition, we created a third set of models with high $S_{\text {post }}$ (upper $95 \%$ confidence limit of calculated $S_{\text {post }}$ ) for this 2014 cohort, with $S a$ and $r$ parameter value combinations as in models 7-10.

Demographic stochasticity in mean $\mathrm{Sa}, \mathrm{S}_{\text {post }}$ and $r$ values was incorporated by creating 10,000 iterations of each model scenario, with each iteration and time period randomly sampling $S a, S_{\text {post }}$, and $r$ values from distributions of 1,000 values each, generated using the mean and one standard deviation of estimates, and averaging across iterations to give an estimated population size.

\section{Results}

\section{Survival and causes of mortality}

Survival probability from release to 1 year post-release was $11.3 \%$ (CI 7.2-17.2\%). Models investigating first-year survival showed that transmitter type was the most important factor affecting survival probability (Model 1, Table 2); however, the second most parsimonious model showed that survival was not related to any of the explanatory factors specified (Model 2, Table 2). Given that $\Delta \mathrm{AICc}<2$ between these two models, we consider both to receive substantial empirical support. Model-averaged estimates showed that individuals fitted with back-mounted radio transmitters survived less well than individuals fitted with other types of transmitter (back-mounted radio transmitter, 5.6 \pm SE 5.9\%; necklace-mounted radio transmitter, $21.1 \pm \mathrm{SE} 12.6 \%$; platform transmitter terminal, $12.5 \pm \mathrm{SE} 4.9 \%$; tail-mounted radio transmitter, $9.5 \pm \mathrm{SE} 4.6 \%$ ) or with no transmitter fitted (11.1 \pm SE 4.6\%). The back-mounted transmitters were fitted to bustards released in 2004 but problems were identified in the harness design used, and therefore these results reflect initial problems in the release methodology. When data from 2004 were excluded from the analysis the most parsimonious model showed that survival was constant $(\mathrm{AICc}=260.1)$. In subsequent years a different harness design was used to attach back-mounted platform transmitter terminals, and these were also fitted by a more experienced researcher.

Model ranking showed that first-year survival probability did not differ between the sexes, between release methodologies, or between years, release sites or month of release (Table 2). Resighting probability in the best-supported models was constant, whereas recovery probability was dependent on transmitter type (Table 2), with individuals fitted with satellite transmitters $(100 \%)$ and back-mounted radio transmitters (80.0 \pm SE 8.9\%) more likely to be recovered than individuals fitted with tail-mounted $(65.5 \pm \mathrm{SE} 7.2 \%)$ or necklace-mounted radio transmitters $(36.3 \pm$ SE $12.2 \%)$ and individuals not fitted with a transmitter $(45.8 \pm \mathrm{SE}$ $7.2 \%)$. After the first year, annual survival rate increased to $88.4 \% \pm$ SE $5.19 \%$ (CI 81.2-95.6\%; $\mathrm{n}=17$ ).

Of 167 individuals released during 2004-2012, 5.4\% were resighted alive in November 2014, 65.3\% were recovered dead and $29.3 \%$ have not been recovered nor resighted alive since November 2013. The most likely cause of death for those individuals recovered was predation $(45.0 \%)$, followed by collision with fences or power lines (28.4\%), with a 
TABLE 3 Reproductive success of great bustards released in the UK during 2004-2014.

\begin{tabular}{|c|c|c|c|c|c|c|c|c|}
\hline & 2004-2008 & 2009 & 2010 & 2011 & 2012 & 2013 & 2014 & Total \\
\hline No. of nesting attempts & 2 & 2 & 4 & 2 & 2 & 2 & 5 & 19 \\
\hline No. of nests hatched & 0 & 2 & 2 & 2 & 0 & 0 & 2 & 8 \\
\hline No. of chicks resighted at $>100$ days old & 0 & 1 & 0 & 0 & 0 & 0 & 0 & 1 \\
\hline No. of chicks recruited into population & 0 & 0 & 0 & 0 & 0 & 0 & 0 & 0 \\
\hline
\end{tabular}

small proportion being related to other causes such as illness or conspecific attack (4.6\%). In $22 \%$ of cases the cause of death was unknown.

As of 30 November 2014 the reintroduced great bustard population comprised five females and four males $>1$ year old. The adults range in age, up to 10 years old for females and up to 7 years old for males. Of the 33 juveniles released in 2014 three have been recovered dead. Similarly to Russian-originated juveniles released in previous years, these Spanish-originated juveniles began to disperse away from their release sites at the end of October, and no juveniles were recorded at release sites by the end of November. In the final 2 weeks of November 2014, 10 juveniles were recorded; seven of these were in the Salisbury Plain area in groups of three and four, and three females were reported on the south coast and Channel Islands, mirroring the movement of previous Russian-originated cohorts.

\section{Reproductive success and recruitment}

From 2007, the year of the first nesting attempt, there has been at least one breeding attempt every year (Table 3). In wild populations males usually breed from 5-6 years of age and females from 2 years of age (Morales \& Martín, 2003). In total, eight breeding females have been recorded during the reintroduction programme, with females breeding from 2 years old for up to 5 consecutive years. However, only 1 of 19 breeding attempts has produced a chick that has been resighted after $>100$ days post hatching, and no wild-reared chicks have recruited into the population (Table 3). Of the 19 breeding attempts $57.9 \%$ failed during incubation, as a result of egg infertility $(27.3 \%$ of failures during incubation), egg predation (36.4\%) and nest desertion $(18.2 \%) ; 18.2 \%$ failed for unknown reasons. During chick-rearing ( $\mathrm{n}=8$ breeding attempts) $25 \%$ of all known losses were attributed to predation; $75 \%$ of losses were from unknown causes.

In $57.9 \%$ of breeding attempts, females chose to nest within predator-exclusion fenced release areas. There was no apparent benefit to hatching success within fenced areas compared to outside (proportion of fertile nests with hatched chicks within fenced areas $=0.62 \pm \mathrm{SE} 0.18, \mathrm{n}=16$; Wilcoxon rank sum test: $W=40, \mathrm{P}=0.4)$. However, of the eight nests with hatched chicks, there was some indication that chicks from nests within fenced areas tended to live longer than chicks from nests outside (mean age of chick at failure: within, 50.6 \pm SE 23.9 days, $n=5$; outside, 18.7 \pm 4.2 days, $n=3$ ), although this was not statistically significant (Wilcoxon rank sum test: $\mathrm{W}=9, \mathrm{P}=0.8$ ).

\section{Population modelling}

Population simulations suggest that with releases of 20 or 40 juveniles annually for the next 10 years and with the current demographic rates, the population size would be $<30$ individuals (scenarios $1 \& 2$, Table 4 , Fig. 1a). If no more juveniles are released, with current demographic rates the population is predicted to decline to $<_{4}$ individuals within 10 years (scenario 3, Table 4, Fig. 1b). Decline is predicted even using recruitment rates observed in wild breeding populations because the high adult mortality in reintroduced birds would not be fully compensated for by recruitment (scenario 5, Table 4, Fig. 1b). Assuming high first-year survival or high adult survival in the UK population, and no recruitment from breeding (scenarios 4, 7 and 8 in Table 4), a slower decline in population is predicted (Table 4, Fig. 1b). Only under the conditions of high survival rates across all ages and recruitment from released individuals equivalent to breeding individuals in wild populations is the current population predicted to increase without further import of eggs or juveniles (scenario 10, Table 4, Fig. 1b).

\section{Discussion}

In the 10-year trial reintroduction of the great bustard to the UK some key reintroduction targets have been achieved, including the hatching of eggs in captivity, the rearing and release of juveniles, lekking behaviour and breeding attempts among adults, and the long-term survival of some individuals in the wild. However, despite some initial target criteria being met and refinements made in the pre-release rearing and release strategy, post-release survival has remained low and no wild-reared chicks have survived to recruit into the population. The initial feasibility study suggested that a viable population might only be achieved after 10 releases of a minimum of 40 individuals (Osborne, 2002); however, this target has not been met. The adult population after 10 years of trial releases comprises nine individuals, and the current demographic rates 
TABLE 4 Population simulations for various scenarios in the reintroduction of the great bustard Otis tarda to the UK, with demographic parameters used (numbers of imported chicks released, $I$; survival probability from release to first year post-release, $S_{\text {post }}, \mathrm{n}=167$; annual adult survival, $S a, \mathrm{n}=17$; recruitment of individuals into the population from breeding of released individuals, $r$ ) and the estimated population size after 10 years $\left(N_{t 10}\right)$.

\begin{tabular}{|c|c|c|c|c|c|}
\hline Scenario & $I$ & $S_{\text {post }}(\%)$ & $\mathrm{Sa}(\%)$ & $r$ & $N_{t 10}$ \\
\hline \multicolumn{6}{|c|}{ Reintroduction continued } \\
\hline 1 & 20 & $11.3 \pm$ SE $0.025^{1}$ & $88.4 \pm$ SE $0.052^{1}$ & $0^{1}$ & $16.9 \pm$ SE 0.02 \\
\hline 2 & 40 & $11.3 \pm$ SE $0.025^{1}$ & $88.4 \pm$ SE $0.052^{1}$ & $0^{1}$ & $29.9 \pm$ SE 0.03 \\
\hline \multicolumn{6}{|c|}{ Reintroduction abandoned (mean $S_{\text {post }}$ ) } \\
\hline 3 & 0 & $11.3 \pm$ SE $0.025^{1}$ & $88.4 \pm$ SE $0.052^{1}$ & $0^{1}$ & $3.9 \pm$ SE 0.007 \\
\hline 4 & 0 & $11.3 \pm$ SE $0.025^{1}$ & $95.6^{1}$ & $0^{1}$ & $8.2 \pm$ SE 0.006 \\
\hline 5 & 0 & $11.3 \pm$ SE $0.025^{1}$ & $88.4 \pm$ SE $0.052^{1}$ & $0.14 \pm$ SE $0.09^{2}$ & $3.9 \pm$ SE 0.007 \\
\hline 6 & 0 & $11.3 \pm$ SE $0.025^{1}$ & $95.6^{1}$ & $0.14 \pm$ SE $0.09^{2}$ & $8.8 \pm$ SE 0.02 \\
\hline \multicolumn{6}{|c|}{ Reintroduction abandoned (high $S_{\text {post }}$ ) } \\
\hline 7 & 0 & $17.5^{1}$ & $88.4 \pm$ SE $0.052^{1}$ & $0^{1}$ & $4.6 \pm$ SE 0.009 \\
\hline 8 & 0 & $17.5^{1}$ & $95.6^{1}$ & $0^{1}$ & $9.6 \pm$ SE 0 \\
\hline 9 & 0 & $17.5^{1}$ & $88.4 \pm$ SE $0.052^{1}$ & $0.14 \pm$ SE $0.09^{2}$ & $10.3 \pm$ SE 0.02 \\
\hline 10 & 0 & $17.5^{1}$ & $95.6^{1}$ & $0.14 \pm$ SE $0.09^{2}$ & $20.4 \pm$ SE 0.02 \\
\hline
\end{tabular}

${ }^{1}$ Parameters from the reintroduced UK population

${ }^{2}$ Parameters from wild populations (Morales et al., 2002)

are insufficient for population viability even with the release of more juveniles. We show that only under the unlikely conditions of high first-year survival, high adult survival, and recruitment equivalent to wild populations elsewhere will this population increase without further imports of eggs or chicks. However, in this scenario and others with high annual adult survival we used the upper confidence limit of the reintroduced population estimates (95.6\%), whereas in well-studied wild populations elsewhere annual adult survival is estimated to be c. $89.7 \%$ (Lane \& Alonso, 2001). Furthermore, unpublished survival values obtained by J.C. Alonso and co-workers from a larger sample from various wild populations in Spain are even lower than these and previously published values (J.C. Alonso, pers. comm.), suggesting that our estimates are overly optimistic. The outcome of the 2014 release is not yet known; however, even with substantial improvement in post-release survival of released individuals, unless there are also significant improvements in adult survival and recruitment rates the population is unlikely to achieve long-term persistence.

We found that first-year survival rates were lower in individuals fitted with back-mounted transmitters than individuals fitted with other transmitter types or no transmitter. However, this was primarily a result of inappropriate mounting methods used in the first year of release (2004). Devices were fitted with straps that passed over the front of the bird; the elastic straps were braided along their length, which is likely to have significantly reduced elasticity. Many individuals fitted with these devices using this methodology were harmed or fatally injured as a result of collisions (44\%), possibly because their movement was restricted by the strapping material. In subsequent years, therefore, back-mounted devices were fitted by more experienced individuals, using a wide elastic band with appropriate tension (Alonso, 2008). Many studies have shown the negative effects of transmitter attachment on energy expenditure, reproduction and survival (Barron et al., 2010); however, in general (excluding the birds released in 2004) we did not find that individuals without a transmitter had a higher first-year survival rate compared to those with transmitters. We do not rule out that transmitter attachments may have a negative effect on the survival and behaviour of released birds but suggest that a combination of behavioural and release condition factors played a greater role in mortality. Also, individuals fitted with satellite transmitters were more likely to be recovered dead than those fitted with radio transmitters or those not fitted with transmitters. Given that many individuals have dispersed away from their release sites over the 10 years of the study, monitoring devices, in particular satellite transmitters, have played a key role in allowing us to monitor individuals. For many individuals released without transmitters, once they left the release area we relied on the general public to report resightings, and only a few individuals were reported each year. Many individuals were not resighted after they left the release area, resulting in a lack of information on the survival, dispersal and cause of death of a significant proportion of released individuals. Such information is essential for any reintroduction project.

Great bustard juveniles remain with their mother for at least 6 months after hatching in the wild (Alonso et al., 1998; Martín et al., 2008). In long-lived species with extended periods of parental care, maternally learned skills (e.g. learning to recognize prey and predators, using habitat or responding to changes in environment, appropriate interactions with conspecifics) are likely to be essential for survival and reproduction (Bennett \& Laland, 2005). In other 


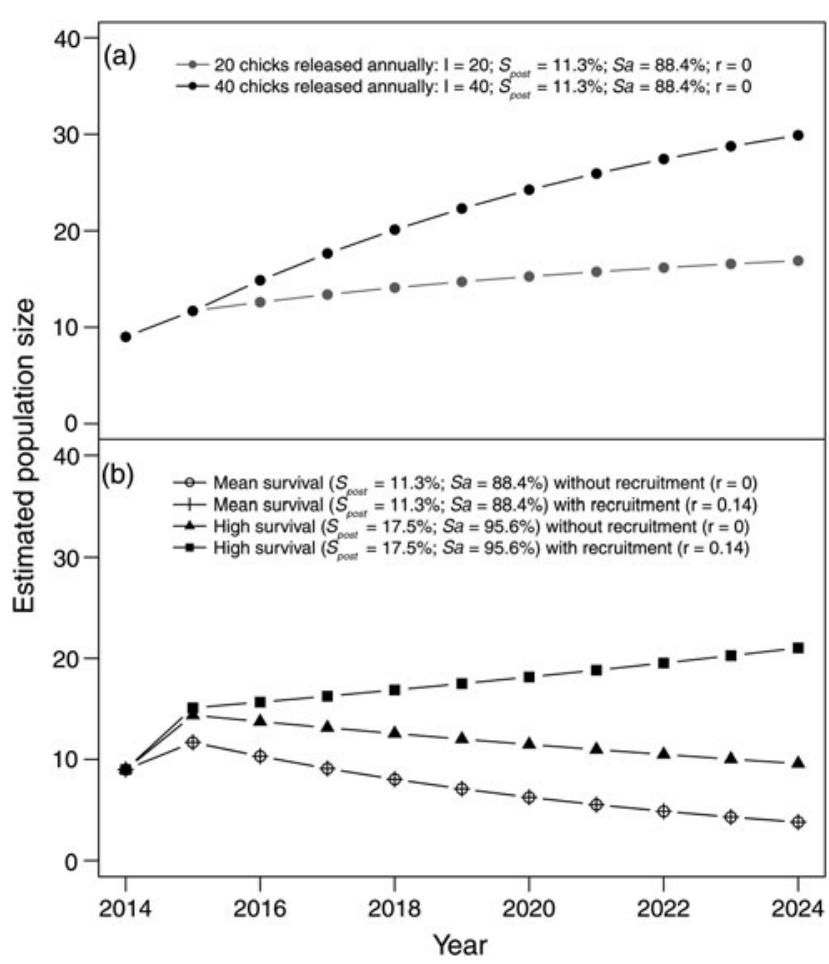

FIG. 1 Estimated population trends for the great bustard Otis tarda in the UK during 2014-2024 under various survival and recruitment scenarios (see Table 4 for parameter values): (a) reintroduction is continued, with 20 or 40 chicks released annually; (b) no more chicks are released, with mean post-release survival with and without recruitment, and with high post-release survival, with and without recruitment.

species, captive-rearing has been shown to produce individuals lacking appropriate anti-predation behaviour (Griffin et al., 2000), and individuals experienced with predators show greater survival than those without experience or with experience only of model predators (van Heezik et al., 1999; Frair et al., 2007). Although informal predator training was trialled during this project, using model foxes in 2010 and dogs in 2012, it is difficult to quantify the effects, if any, of this training as it was not carried out in a standardized manner. However, released juveniles associating with older individuals, either single females or small female or mixed groups, shortly after release or in the spring following release have generally been more long-lived than those dispersing individually or associating more closely with other released juveniles; social learning from older individuals is therefore likely to be critical to improving post-release survival. In wild populations in Spain, male chicks that were better fed by their mothers were more readily integrated into adult male groups (Alonso et al., 1998). In the UK population, however, it is unclear what determines whether a juvenile will be accepted into an adult group, or whether some juveniles simply choose to remain with other juveniles, but the ratio of juveniles accepted to adults within a group is generally c. 1-2 juveniles per adult. With low numbers of adults surviving, it is therefore unlikely that large numbers of released juveniles in the future will benefit from social learning.

Collisions are a major cause of mortality in wild bustard populations (Janss, 2000; Martin \& Shaw, 2010) but captive-reared individuals may be particularly vulnerable because of differences in musculature, feather condition and flight performance (Robertson et al., 1993; LiukkonenAnttila et al., 2000; Hess et al., 2005). Take-off ability may affect success in escaping predators, and this may vary between individuals, depending on their energy resources and body condition (Putaala et al., 1997). Biometric information was collected from individuals at each release, and in 2011 we also began collecting systematic data on flight feather condition at release, following concerns over the impact of prerelease condition on post-release survival. It is likely that feather condition played a significant role in mortality from predation and collision (KA, pers. obs.). Importing juveniles from Russia to the UK may have affected their condition, as it involved a 48-hour journey in crates, a 30-day quarantine period in restrictive facilities that prohibited practice flight, an unnatural diet, and the stress of regular human disturbance and handling. In 2012, eggs were imported, limiting the quarantine period to the first weeks following hatching, and with the use of dehumanization suits and larger pen areas, chicks could be exercised and were able to feed in specially managed habitat. However, problems with feather condition, probably because their diet contained too little protein and possibly too little vitamin $\mathrm{D}$, meant that these chicks were held back and released the following spring. Nonetheless, given the greater freedom for juveniles to exercise flight musculature and forage naturally, and also the reduction in handling, the project team considered importing eggs to be an improvement over importing chicks.

Poor survival of individuals from release to 1 year postrelease was highlighted as a major factor limiting success in the first years of the project, with predation and collision being the major causes of mortality (Burnside et al., 2012). Attempts were made to address predation risk by establishing new release sites that were considered to have smaller or controllable predator populations. As released individuals frequently dispersed away from release sites, showing similar behaviour to individuals from their source population (Watzke, 2007), the rearing programme was extended beyond release with dehumanization suits in an attempt to improve group cohesion around release sites and assist with the learning of foraging activities. In addition, supplemental food was provided at release sites in an attempt to reduce dispersal (Williams et al., 2013) and assist establishment. None of these changes in later years of the project were found to improve post-release survival significantly, however, with individuals continuing to disperse away from release sites in their first winter. In 2014, attempts were made 
to reduce dispersal behaviour by collecting eggs from populations in Spain, where individuals do not tend to disperse as far as individuals from Russian populations (Martín et al., 2008; Palacín et al., 2011); however, as of the end of November 2014, no individuals from this cohort remain at release sites and at least four have been resighted on the south coast and on the Channel Islands, near to locations of resightings from previous years. The evolution of dispersal in animal populations has been associated with changes in environmental conditions, with greater seasonality tending to result in increased dispersal behaviour (Johnson \& Gaines, 1990). Given that individuals released from both Russian and Spanish populations have dispersed south in autumn, it is possible that these dispersal movements are in response to unfavourable winter conditions such as low temperature and high rainfall, which may have a negative impact on energy expenditure and food availability (e.g. through winter senescence in many plant species). If this is the case, and released individuals continue to disperse away from the release area, it will limit the capacity of the reintroduction project to improve post-release survival rates and achieve population viability; however, at present the effect of the change in donor population on post-release survival is unknown.

Although surviving individuals have made breeding attempts in all years since 2007 , no chicks have been recruited into the population because of failures during incubation and chick-rearing and, in one case, during the first winter. In two cases females were predated during chick-rearing, highlighting the vulnerability of breeding females and the importance of protecting them during this period. Given our small dataset on reproductive rates it is difficult to draw conclusions on future management to improve reproductive output, but we found some indication that chicks from nests within fenced areas survived slightly longer than chicks from nests outside fenced areas, probably as a result of reduced predation pressure and the creation of suitable nesting habitat. However, temporarily fencing areas to provide protection from mammalian predators involves human disturbance around the nesting area (e.g. regular changes in power supplies for an electric fence), which may increase the likelihood of nest desertion. Improving reproductive rates is one of the greatest challenges to the success of the reintroduction project and needs further investigation into the causes of nest failure during incubation, careful consideration of fencing nests found outside fenced areas, and further investment in the creation of nesting habitat through agri-environment schemes or land acquisition, including permanently fenced areas. An assessment of whether invertebrate populations in southern England are sufficient to support the required level of productivity in great bustards is also required. Adult survival may increase naturally if wild-born juveniles are recruited into the population, as such birds are likely to benefit from maternally learned skills, and if larger group sizes develop.

Reintroduction programmes should always include a significant monitoring component (Seddon et al., 2007; Ewen et al., 2012); without monitoring, the results or failure of the project may not be clear. They should also involve regular evaluation of the progress towards specific targets (Armstrong \& Seddon, 2008). We assessed project results annually and performed more extensive reviews every 5 years. Recommendations from these reviews were not always acted upon by conservation practitioners, however, possibly limiting the success of the project. Launching or continuing a reintroduction of a long-lived species with a complex biology needs additional scrutiny, as these species may be more prone to failure than $r$-selected species. Nonetheless, reintroductions can generate a wealth of data that can reveal much about ecology, behaviour and life history, and thus inform future conservation programmes. The monitoring work presented here was undertaken as part of a LIFE-funded project that came to an end in 2014. It can be used to help inform decision making by those seeking to take the project forward in 2015 and beyond, although as the authors are no longer directly involved we are unable to comment further on future plans.

The great bustard has declined across large parts of its global range, and recent intensive conservation efforts have achieved population increases only in very small parts of that range. It is a long-lived species with complex social behaviour, and struggles to survive in a humandominated agricultural landscape; thus a reintroduction to southern England was always going to be an ambitious project. During the 10 years of the trial reintroduction some significant milestones were achieved, and the rearing and release methodologies have been improved and refined. Despite this progress, current demographic rates remain too low for establishment and long-term persistence of a wild population. At the end of the 10-year trial period it is clear that without substantial improvements in key demographic parameters, the successful re-establishment of this species in southern England is unlikely.

\section{Acknowledgements}

The Great Bustard Reintroduction was started by the Great Bustard Group in 2004, and the University of Bath joined the project in 2005. The LIFE+ partnership of the Great Bustard Group, Royal Society for the Protection of Birds, University of Bath, and Natural England was established in 2010 and ended in 2014. We thank Leigh Lock for his guidance on the project and for comments on the manuscript. We thank the Great Bustard Group for their efforts in importing, rearing and releasing individuals for the reintroduction project. We thank Paul Goriup for his helpful 
comments and suggestions. We gratefully acknowledge Dr Anatoli Khrustov, Director of the A.N. Severtsov Institute of Evolution and Ecological Problems (Saratov Branch), Russian National Academy of Science, for his role in making the reintroduction possible. We thank the project staff, volunteers and general public for collecting data on great bustards in southern England, and Juan Carlos Alonso and an anonymous reviewer for their valuable comments. This work was funded by LIFE+ consortium grant LIFEog/ NAT/UK/oooo2o.

\section{References}

Alonso, J.C. (2008) Guidelines for radio-tracking Great Bustards. Bustard Studies, 7, 81-95.

Alonso, J.C., Martín, E., Alonso, J.A. \& Morales, M.B. (1998) Proximate and ultimate causes of natal dispersal in the great bustard, Otis tarda. Behavioral Ecology, 9, 243-252.

Armstrong, D.P. \& Reynolds, M.H. (2012) Modelling reintroduced populations: the state of the art and future directions. In Reintroduction Biology: Integrating Science and Management (eds J.G. Ewen, D.P. Armstrong, K.A. Parker \& P.J. Seddon), pp. 165-222. Wiley-Blackwell Publishing, Chichester, UK.

Armstrong, D.P. \& Seddon, P.J. (2008) Directions in reintroduction biology. Trends in Ecology \& Evolution, 23, 20-25.

Barron, D.G., Brawn, J.D. \& Weatherhead, P.J. (2010) Meta-analysis of transmitter effects on avian behaviour and ecology. Methods in Ecology \& Evolution, 1, 180-187.

Bennett, JR, G.G. \& LALAnd, K.N. (2005) Social learning in animals: empirical studies and theoretical models. BioScience, 55, 489-499.

BURNHAM, K.P. (1993) A theory for combined analysis of ring recovery and recapture data. In Marked Individuals in the Study of Bird Population (eds J.D. Lebreton \& P.M. North), pp. 199-213. Birkhauser Verlag, Basel, Switzerland.

Burnham, K.P. \& Anderson, D.R. (1998) Model Selection and Multimodel Inference: A Practical Information-Theoretic Approach, 2nd edition. Springer-Verlag, New York, USA.

Burnside, R.J., Carter, I., Dawes, A., Waters, D., Lock, L., Goriup, P. \& Székely, T. (2012) The UK great bustard Otis tarda reintroduction trial: a 5-year progress report. Oryx, 46, 112-121.

Doherty, P.F., White, G.C. \& Burnham, K.P. (2012) Comparison of model building and selection strategies. Journal of Ornithology, 152, 317-323.

Ewen, J.G., Armstrong, D.P., Parker, K.A. \& Seddon, P.J. (eds) (2012) Reintroduction Biology: Integrating Science and Management. Wiley-Blackwell Publishing, Chichester, UK.

Fischer, J. \& Lindenmayer, D.B. (2000) An assessment of the published results of animal relocations. Biological Conservation, 96, $1-11$.

Frair, J.L., Merrill, E.H., Allen, J.R. \& Boyce, M.S. (2007) Know thy enemy: experience affects elk translocation success in risky landscapes. The Journal of Wildlife Management, 71, 541-554.

Griffin, A.S., Blumstein, D.T. \& Evans, C.S. (200o) Training captive-bred or translocated animals to avoid predators. Conservation Biology, 14, 1317-1326.

Griffith, B., Scott, J.M., Carpenter, J.W. \& Reed, C. (1989) Translocation as a species conservation tool : status and strategy. Science, 245, 477-480.

Hess, M.F., Silvy, N.J., Griffin, C.P., Lopez, R.R. \& Davis, D.S. (2005) Differences in flight characteristics of pen-reared and wild prairie-chickens. The Journal of Wildlife Management, 69, 650-654.
IUCN (1998) Guidelines for Re-introductions. Prepared by the IUCN SSC Re-introduction Specialist Group, IUCN, Gland, Switzerland, and Cambridge, UK.

IUCN (2014) IUCN Red List of Threatened Species. Http://www. iucnredlist.org [accessed 18 December 2014].

JANss, G.F.E. (2000) Avian mortality from power lines: a morphologic approach of a species-specific mortality. Biological Conservation, 95, 353-359.

Johnson, M.L. \& Gaines, M.S. (1990) Evolution of dispersal: theoretical models and empirical tests using birds and mammals. Annual Review of Ecology and Systematics, 21, 449-48o.

LANE, S.J. \& Alonso, J.C. (2001) Status and extinction probabilities of great bustard (Otis tarda) leks in Andalucía, southern Spain. Biodiversity and Conservation, 10, 893-910.

Liukkonen-Anttila, T., SaArtoala, R. \& Hissa, R. (2000) Impact of hand-rearing on morphology and physiology of the capercaillie (Tetrao urogallus). Comparative Biochemistry and Physiology Part $A, 125,211-221$.

Martín, C.A., Alonso, J.C., Alonso, J.A., Palacín, C., Magaña, M. \& MARTín, B. (2007) Sex-biased juvenile survival in a bird with extreme size dimorphism, the great bustard Otis tarda. Journal of Avian Biology, 38, 335-346.

Martín, C.A., Alonso, J.C., Alonso, J.A., Palacín, C., Magaña, M. \& MARTín, B. (2008) Natal dispersal in great bustards: the effect of sex, local population size and spatial isolation. Journal of Animal Ecology, 77, 326-334.

Martin, G.R. \& Shaw, J.M. (2010) Bird collisions with power lines: failing to see the way ahead? Biological Conservation, 143, 2695-2702.

Morales, M.B., Alonso, J.C. \& Alonso, J.A. (2002) Annual productivity and individual female reproductive success in a great bustard Otis tarda population. Ibis, 144, 293-300.

Morales, M.B. \& Martín, C. (2003) Otis tarda Great Bustard. In Birds of the Western Palearctic Update (eds S. Cramp \& K.E. L. Simmons), pp. 217-232. Oxford University Press, UK.

Oparin, M.L., Kondratenkov, I.A. \& Oparina, O.S. (2003) Abundance of the Transvolga population of great bustard (Otis tarda L.). Biology Bulletin, 30, 562-569.

Oro, D., Margalida, A., Carrete, M., Heredia, R. \& Donázar, J. A. (2008) Testing the goodness of supplementary feeding to enhance population viability in an endangered vulture. PLOS ONE, 3 (12), e4084.

Osborne, P.E. (2002) Application to the Department for Environment, Food and Rural Affairs for a Licence to Re-introduce Great Bustards. Great Bustard Group, Salisbury, UK.

Palacín, C. \& Alonso, J.C. (2008) An updated estimate of the world status and population trends of the great bustard Otis tarda. Ardeola, 55, 13-25.

Palacín, C., Alonso, J.C., Alonso, J.A., Magaña, M. \& Martín, C.A. (2011) Cultural transmission and flexibility of partial migration patterns in a long-lived bird, the great bustard Otis tarda. Journal of Avian Biology, 42, 301-308.

Putalia, A., Oksa, J., Rintamäki, H. \& Hissa, R. (1997) Effects of hand-rearing and radiotransmitters on flight of gray partridge. The Journal of Wildlife Management, 61, 1345-1351.

R Development Core Team (2013) R: A Language and Environment for Statistical Computing. R Foundation for Statistical Computing, Vienna, Austria.

Robertson, P.A., Wise, D.R. \& Blake, K.A. (1993) Flying ability of different pheasant strains. The Journal of Wildlife Management, 57 , $778-782$.

SARrazin, F. \& BARbault, R. (1996) Reintroduction: challenges and lessons for basic ecology. Trends in Ecology \& Evolution, 11, 474-478. 
Schaub, M., Zink, R., Beissmann, H., Sarrazin, F. \& Arlettaz, R. (2009) When to end releases in reintroduction programmes: demographic rates and population viability analysis of bearded vultures in the Alps. Journal of Applied Ecology, 46, 92-10o.

SEddon, P. (1999) Persistence without intervention: assessing success in wildlife reintroductions. Trends in Ecology \& Evolution, 14, 503.

Seddon, P., Armstrong, D.P. \& Maloney, R.F. (2007) Developing the science of reintroduction biology. Conservation Biology, 21, 3O3-312.

Teixeira, C., de Azevedo, C., Mendl, M., Cipreste, C. \& Young, R. (2007) Revisiting translocation and reintroduction programmes: the importance of considering stress. Animal Behaviour, 73, 1-13.

van Heezik, Y., Seddon, P.J. \& Maloney, R.F. (1999) Helping reintroduced houbara bustards avoid predation: effective anti-predator training and the predictive value of pre-release behaviour. Animal Conservation, 2, 155-163.

WATZKe, H. (2007) Results from satellite telemetry of great bustard in the Saratov region of Russia. Bustard Studies, 6, 83-98.

White, G.C. \& Burnham, K.P. (1999) Program MARK: survival estimation from populations of marked animals. Bird Study, 46, Supplement 1, 120-138.
Williams, D.R., Pople, R.G., Showler, D.A., Dicks, L.V., Child M.F. \& Sutherland, W.J. (2013) Bird Conservation, and edition. Pelagic Publishing, Exeter, UK.

Wolf, C.M., Griffith, B., Reed, C. \& Temple, S.A. (1996) Avian and mammalian translocations: update and reanalysis of 1987 survey data. Conservation Biology, 10, 1142-1154.

\section{Biographical sketches}

Kate Asнв воок is interested in biodiversity conservation and specializes in using modelling to inform evidence-based conservation management. ANDREW TAYLOR and Louise JANE worked for the RSPB on monitoring and designing agri-environment schemes for bird populations across the UK and were part of the reintroduction project during 2011-2014. IAN CARTER has worked as an ornithologist with Natural England (and predecessors) for over 20 years and has a particular interest in bird reintroductions. TAMÁS SZÉKELY is interested in biodiversity conservation and specializes in avian breeding systems. 